\title{
Relevance Analysis and Significance Test Based on Computer Informatization
}

\author{
Cuixia Yi \\ School of Physical Education, Shaanxi Normal University, Xi'an, China \\ yi_cuixia@126.com
}

\begin{abstract}
Keywords: mean differences; correlation analysis; significance test; individual differences; cognitive development; statistical power; confidence level
\end{abstract}

\begin{abstract}
With the development of society, individuation of modern middle school student tends to obvious, the contact between student personality difference and personality development should be paid attention, especially in process of physical education. This paper was mainly aimed at the present situation of modern middle school physical education and cognition of personality difference and development in the process of physical education, applied the principle and method of mean differences significance test statistical test ability and effect estimation, tested the test power and effect of mean difference significance, practiced individuation on physical education, carried on association analysis to its personality effect, then finally arrived at conclusion that positive feedback of teaching efficiency will turn up if personality difference and development is paid enough attention in modern physical education, put forward concrete measures of promoting personality development and adapting physical education, provided theory basis and reference for student personality development in physical education.
\end{abstract}

\section{Introduction}

With the development of society, students' personality becomes more and more different, and education pays more attention to the cultivation of students' distinctive and perfect personality and innovation ability. Quality-oriented education is the theme of modern education, with the constant development of society, economy and culture, personality of modern middle school student is obvious, characteristic of student groups is prominent[1]. Physical education is one of a dispensable subject in modern secondary education, it has positively impact in promoting personality development of students, makes a solid foundation for cultivating integrated arts all-round development of new talents who are needed by modern society, it can provide an effective guarantee for cultivating complex talents who is innovative and have their own personality characteristic. The target of physical education that traditionally aims at physical exercise should be changed, physical education should combine both physical and mental exercise under modern education system, promotes physical health of students and their mental health at the same time by physical education, aims at cultivating social adaptation and physical and mental comprehensive quality of student[2]. Relative to teachers, they need to realize the whole influence and importance of students individual differences to their all-round development in the process of physical education, change their teaching ideas and thoughts, enrich teaching content, broaden teaching thinking, stimulate students' learning interest and increase mental ability in the procress of physical education, make them try their best to be a person with both moral and academic skills.

\section{The Cognition of Students Personality Difference and Development in Process of Physical Teaching}

Personality is a synthesis of one's own consciousness tendency, personal temperament, personal characteristic, personal ability, personal tendency includes personal needs, needs motivation, hobbies and interests, self-confidence and personal sense. There are various of reasons to influence personal personality development in real life, two main reasons are biological heredity and environment influence[3]. Students in secondary school come in a period of puberty, it is also an important stage of growing healthily to students, secondary education plays a part in two aspects that are formation 
and development of students' personality, mainly is the optimization of student personality characteristic individuation, makes students move forward positively by education, education plays an intensive role in the development of students' personality, strengthens students' personality optimization development by education, makes students set up a right life ideal and goal and on the right path in life. The specific processes are as follows.

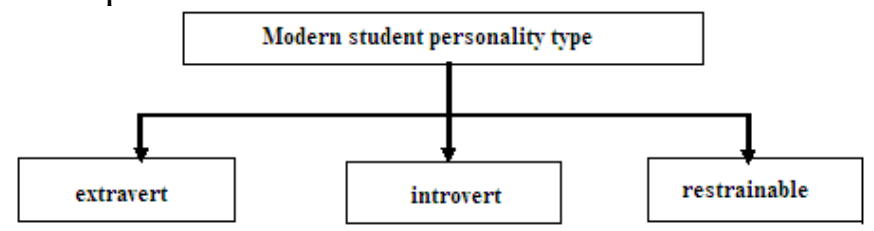

Figure 1. The cognition process of education in student personality difference and development

Relative to secondary school physical education in classroom teaching, the entire teaching venues is relatively open, teaching methods are flexible, communications between students are frequent, teamwork and personal performance are valued, its teaching characteristics provide an excellent platform for reflecting students' personality and optimizing personality development, therefore physical education will become an important teaching part of secondary school focusing on students' personality difference and development.

In terms of the essence of physical teaching content, physical teaching fully reflects target of students' personality development, every student individual reflects his own mental characteristic in process of physical teaching, respective personality difference will appear at this moment, teachers can carry on targeted teaching on mental characteristic of every student individual, that is teaching students in accordance with their appetite, realize every student's potential, excavate their learning interests and motivation[4]. Physical teachers only know every student's mentality and learning motivation in the process of teaching, do they can further guide students to participate in activity of physical learning from students' mentality, enhance students' mental ability and comprehensive quality. Physical teachers only deepen their own cognition about students' personality difference and development can they positively make a great contribution to modern physical education, modern students' personality can be divided into three types generally, as following figure shown.

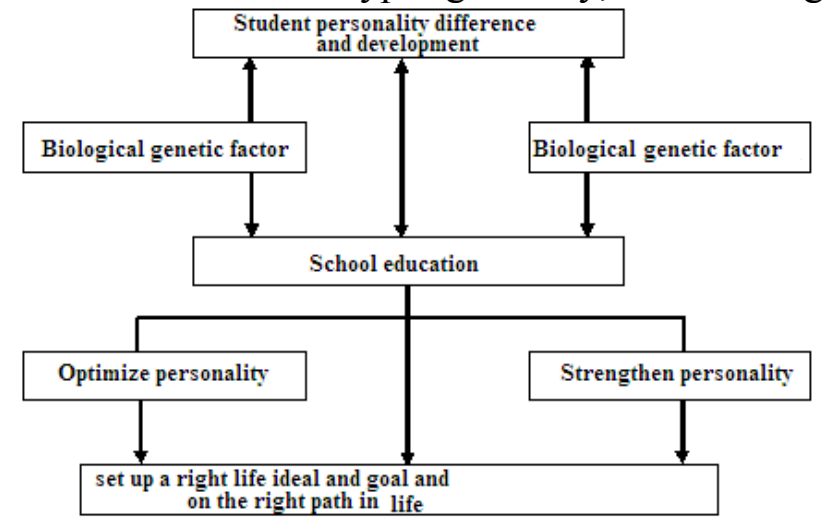

Figure 2. The contemporary middle school students' personality types

As Figure 2 shown, modern students' personality can be divided into 3 types, they are extravert type, introvert type and restrainable type, extravert type shows figures of quick mind reaction in physical teaching activity, having strong desire of showing oneself, communicating well with teachers and classmates while emotional and easily excited and impulsive; introvert type of students have stubborn personal mind, can accomplish teaching task as demand to some degree, but can't communicate with teachers and classmates positively, and they are good at solving problem on their own, do not seek help; restrainable type of students are react slowly, they don't have enough strain capacity in learning process, and it can be easily with negative mentality, rarely communicate with teachers and classmates.

Teachers need to grasp students' mentality in real teaching process, clearly know students' personality type, and teach them in accordance with their appetite, fully optimize students' personality characteristics to move toward all-round development for themselves[5,6]. In terms of extravert type of students, teachers should cultivate their self-control ability and good positive quality, carry forward merits, overcome drawbacks on the base of proper encouragement.;As for introvert type of students, teachers should fully affirm the merit of they can accomplish teaching task 
positively and steadfastly, encourage that type of students to communicate with teachers and classmates positively, be adept in sharing, believe the strength of collective; as for restrainable type of students, teachers should pay attention to communicate and exchange with them inwardly, carry on targeted teaching, enhance their confidence, make them taste the joy of success on the basis of accomplishing teaching content and sharing with others[7].

\section{Analysis on Students Personality Mean Difference Test}

A. Statistics on personality difference of Physical Education

In order to study the difference of students personality systematically, a study was carried on among 200 students selected from A and B school.Let them choose physical learning target, skill pattern and exercise time according to their own hobbies and interests, personality and speciality, and comprehensive abilities, study relative physical course independently, test situation as Table1.

TABLE I. Personality difference statistical form

\begin{tabular}{|l|l|l|}
\hline school & Personality difference average & $\begin{array}{c}\text { General personality difference } \\
\text { standard deviation }\end{array}$ \\
\hline A & 115 & 15 \\
\hline B & 110 & 15 \\
\hline
\end{tabular}

Usually set null hypothesis which is need to be tested as $\mathrm{P} 0: \mathrm{N} 1=\mathrm{N} 0$, or $\mathrm{N} 1-\mathrm{N} 0=0$, when test differences in the average, this is assumption that $\mathrm{N} 1$ and $\mathrm{N} 0$ have no significant difference statistically and substantially between two averages; while set the reverse side of null hypothesis as $\mathrm{P} 1: \mathrm{N} 1 \neq \mathrm{N} 0$, this is assumption that $\mathrm{N} 1$ and $\mathrm{N} 0$ have significant difference statistically and substantially between two averages. According to the result of assumption test, no matter what null hypothesis is not rejected, it is possible to make mistake $\alpha$ or $\beta$. In general, it is impossible that both $\alpha$ and $\beta$ increase or decrease at the same time, as Table 2 and Figure 1 shown, correlation between $\alpha$ and $\beta$.

\begin{tabular}{|l|l|l|}
\multicolumn{1}{c}{ TABLE II. probable test result } \\
\hline & \multicolumn{1}{c|}{ Not be rejected P0 } & Be rejected P0 \\
\hline P0 is true & confidence $=1-\alpha$ & Test level $=\alpha$ \\
\hline P0 is false & Second kind error probability $=\beta$ & Statistical test ability1- $\beta$ \\
\hline
\end{tabular}

B. Estimation of mean differences significance test statistical test ability

In the process of physical education, physical teachers need to know deeply the difference situation of student individual, according to student individual personality characteristic, put forward relative study requirement pointedly, physical teachers achieve student subjectivity according to teaching requirement feedback, let every student is able to participate in physical teaching activity in accordance with their own personality characteristics, achieve their personality development, further achieve all-round self-development.

According to Table 1, data can be known, $\mathrm{n} 1=100, \mathrm{n} 2=100, \mu 1=115, \mu 2=111, \sigma 1=15, \sigma 2=15$, build assumption $\mathrm{P} 0: \mathrm{N} 1=\mathrm{N} 0, \mathrm{P} 1: \mathrm{N} 1 \neq \mathrm{N} 0$, for statistical magnitude $\mathrm{Z}$, here comes following formula[8]:

$$
Z=\frac{(\mu 1-\mu 2)-(N 1-N 2)}{\sqrt{\frac{\sigma 1^{2}}{n 1}+\frac{\sigma 2^{2}}{n 2}}}
$$

Put data into formula (1) comes to the formula[9]:

$$
Z=\frac{(\mu 1-\mu 2)-(N 1-N 2)}{\sqrt{\frac{\sigma 1^{2}}{n 1}+\frac{\sigma 2^{2}}{n 2}}}=\frac{115-111}{15^{2}}+\frac{15^{2}}{100}=1.89
$$

When the significance level $\alpha=0.05$, its critical value is $\left|Z_{\frac{\alpha}{2}}\right|=1.96$, due to $Z=1.89<\left|Z_{\frac{\alpha}{2}}\right|$, the decision made in normal situation is deduction difference is not caused by accidentally under no fully grasp, in other words, there is no sufficient reason to reject null hypothesis, but accepting null hypothesis. It follows that the estimation of differences between two schools are relatively reliable, its differences are caused by accidentally. 
As what mentioned before, $\delta$ means some certain specific alternative in two independent sample averages and difference significance test, assume that the distribution of expected value $\mathrm{Z}$, while sample average, the expected value of $\mathrm{N} 1$ is $\mu 1$, sample average, the expected value of $\mathrm{N} 2$ is $\mu 2$, relatively, calculate the mean differences, the formula of value $\delta$ in significance test[10]:

$$
\delta=\frac{\mu 1-\mu 2}{\sqrt{\frac{\sigma 1^{2}}{n 1}+\frac{\sigma 2^{2}}{n 2}}}
$$

The horizontal relationship between statistical test ability and $\alpha$ can be further understood by the following Figure2. This Figure shown, for any value $\delta$, and represented by abscissa axis, relevant to that value $\delta$, the value of difference statistical test ability, its transformation will turn out to be function of $\alpha$.

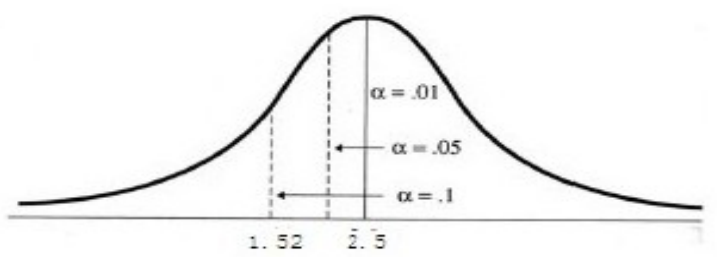

Figure 3. $\quad \alpha$ horizontal relation figure

Estimate every student individual's personality development by mean difference significance test statistical test ability, it can promote students' merits in physical education practice, help students to improve disadvantages, promote students personality development in all directions and diversification[11]. Excavate positive and negative factors of student individual personality in process of test, plan students' physical education efficiently, the whole teaching process has some certain pertinence in the city, helps students realize their shortage, promote their positive side to overcome the negative one, and makes students move forward positively and healthily.

\section{Measures of Promoting Students Personality Development in Physical Education}

Promote students personality development in physical education is to promote self-actualization of every student in practice teaching, so methods of secondary physical teaching should be paid attention, firstly, relation of equality between students and teachers should be built, promote subjective initiative of teachers and students, inspire students study type thinking, specifically, promote middle school students personality development in physical teaching should pay attention to following points, the following figure shown specially.

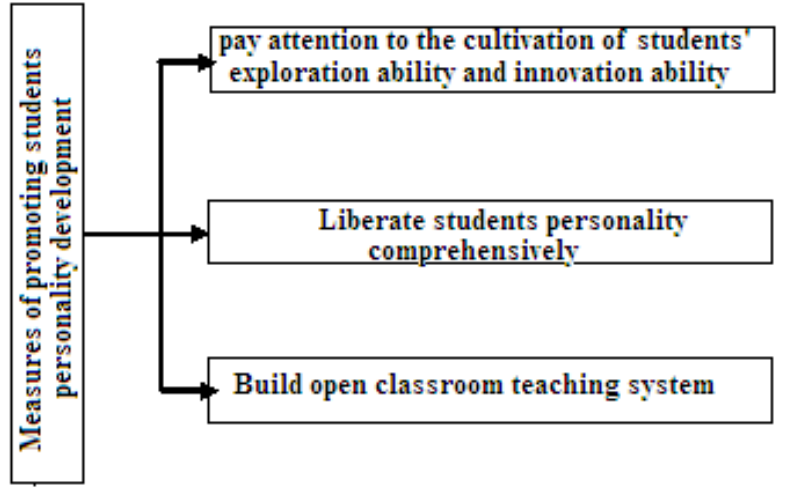

Figure 4 Measures of promoting students personality development

As Figure 4 shown, physical teaching should pay attention to the cultivation of students' exploration ability and innovation ability, teachers should give students chance to show themselves in process of teaching, fully promote their autonomy, stimulate their interests in physical learning, make them build their own knowledge hierarchy in process of study, and exert their personal inquiry learning ability, create their own learning style; teachers should set up right professional concept in the process of physical teaching, put students' personality development on their heart, be good at observe students' mental change, grasp students' personality characteristics, and create positive teaching atmosphere of learning for students[12].Let students fully promote their own advantages 
and do physical exercise according to their personality characteristics, let students set up independent self-learning consciousness, participate in learning activity positively, feel charisma of physical can be learned, deeply communicate learning experience to develop good personality characteristics of independently study

\section{Conclusion}

Physical education plays a role in the development of middle school student personality difference optimization, so physical workers need to let students are able to open their learning thinking, exploit learning thought, promote their own learning skills in the process of learning during teaching. To own new breakthrough understanding, help students grasp learning point in the process of learning, overcome thinking difficulty, grasp knowledge point and thinking consciousness at the same time on both macroscopical and microcosmic view, make it better to integrate learning content, adjust learning method, makes study of physical course and other course can achieve more excellent grades, makes students possess innovation consciousness, it's a stating point and drive of being engaged in innovative activity, and mentality tropism of discovering problem and positive exploration.

\section{References}

[1] Li Jianzhou.Psychology of Physical Education.Higher Education Press, 2007:336-345.

[2] Qu Zonghu.Modern Education Theory and Physical Education.People's Publishing House,2008:173-175.

[3] Wu Yexian. New Education Theory. Teaching Science Press, 2011,261-264.

[4] Ming Qing. School Education and Personality Development. Knowledge press ,2011:43-56.

[5] Fan Xiangqian. Embodiment of Physical and Healthy Course Students School Record Assessment. Physical Education, 2012(4):12-14.

[6] Qiu Laidong. Exploration of Sports Personality Education.Education Science \& Culture Magazine, 2007(11):103-106..

[7] Ding Yongjiang, Lin Zongde. Physical Education Should Pay Attention to Personality Development. Physical Research, 2006 (3):67-70..

[8] Zhao Linxian.Talk about How to Carry on Personalization Education to Students in Physical Education. Journal of Yanbian Education College, 2011(4):57-59.

[9] Chen Jianhua, Ou Haiyan. The Role of Personalization Education in Physical Education. Sports Science and Technology, 2010(4):112-116.

[10] Zhang Haiping. Calling for Physical Teaching "Personalization". Sports Mentorship, 2005(5):78-83.

[11] Shen Jianhua, Xu A'gen. Shanghai the Students Physical Fitness Curriculum Standard Interpretation. Children Press, 2011:38-59.

[12] Ji Liu. Psychology of Physical Education. Higher Education Press, 2006:213-219. 